\title{
Plan of Leprosy Control in Nepal being Carried out in a General Hospital*
}

\author{
J. C. PEDLEY \\ Medical Officer, United Mission Hospital, Tansen, Palpa, Nepal
}

Addressing the closing session of the Ninth International Leprosy Congress in London, Dr. Stanley Browne said: "There is no single world-wide plan for dealing with leprosy, but in every area there is a plan which is better than others".

It would appear from all the available evidence that the endemicity level of leprosy in Nepal is not less than 10 per 1000 and is probably as high as 15 per 1000 . The population of Nepal is reckoned to be about 10 million. Thus, there may be about 150,000 people suffering from leprosy in the whole country. Two factors make the prevention and control of leprosy in Nepal very difficult: (1) Poor communications. Throughout most of the country there is scarcely any other means of travel than on foot by mountain trails. (2) Repressive leprosy laws. If these laws are enforced, a patient can be deprived of his land, made to leave his village, and go and live for the rest of his life in a government leprosy colony where there is no segregation of the sexes. These laws make the control and prevention of leprosy very difficult, as people who contract the disease are naturally afraid to disclose it.

In these conditions, what is the "plan that is better than others" for carrying out a programme of leprosy control in Nepal? A simple one, which is to be described, has been worked out in the leprosy wing of a general hospital situated in the mountains of western Nepal. My thanks are due to the Leprosy Mission for seconding me to the United Mission in Nepal so that I might have the opportunity to carry out leprosy work in this context for nearly 10 years.

*Received for publication 9 July, 1969.
Leprosy patients attend the out-patients department like any other patient. In-patient care is also provided for treatment of trophic ulcers of the foot, reactive states, and reconstructive surgery. This aspect of the work has become widely known and patients continue to attend in steadily increasing numbers. Case-finding surveys into the remote villages from which they come are unlikely to take place for a very long time to come, but in the meantime a doctor experienced in leprosy and settled in one place over a long period can build up confidence and draw people with the disease out of their villages to come for treatment.

Many of our patients are anxious to protect their families from contracting the disease, and some patients have asked me to let them have preventive medicine to give to their children, even before I suggested it. I believe that it is right to uncover this anxiety and exploit it for the purpose of instituting preventive treatment. Thus, during the past 18 months it has become a firm practice not to allow a patient, no matter what type of leprosy he has, to leave the hospital until his family have been listed and preventive treatment has been prescribed for all close contacts. This means that to any close contact aged 4 years and over, $50 \mathrm{mg}$ of DDS per week is given, while children under 4 years and above the age of 1 year are given $20 \mathrm{mg}$ per week. Children under 1 year of age will receive the drug in the breast milk (Tuason and Rivera, 1965).

Up to the time of writing, nearly 1000 close contacts of 250 patients have been put on preventive treatment, and this number will steadily increase to the end of the year because: 
(a) there are several hundred more patients on the register whose close contacts have not yet been inquired into, and (b) there will be more close contacts of new patients who will be added to the register before the year is out. The average distance which these 250 patients travel to the hospital is 35 miles, and by the time they get back home again the round journey will have taken them 8 or 9 days. Not a few of them travel distances of 100 to 150 miles to reach the hospital. Therefore, I rarely give less than 6 months' to 1 year's supply of curative and preventive DDS, which costs between 3 and 8 shillings a year for one family. Of these 1000 close contacts, the proportion of children to adults averages approximately 3 to 1 . It would not be possible at the present time to reach all these contacts by personal visitation, but we can and do reach them through out patients who, in a sense, become our paramedical workers.

While I am unable to give a critical appraisal of this preventive work, my belief in the value of taking DDS prophylactically is based on experience gained while acting as medical officer to a government leprosy colony in this country. The number of children born annually in the colony increased from 20 to 69 over a period of 10 years. All the children were given regular prophylactic doses of DDS during this time. I never saw any ill effects of the drug, and not one of the children developed leprosy, although many were living in close contact with patients with very advanced lepromatous disease.

As regards the emergence of drug resistance to DDS, I have yet to meet an example of this. The occurrence of it is regarded as rare by some competent workers (Pettit and Rees, 1964). I therefore believe that this plan of bringing close contacts under preventive treatment can do no harm, and may do much good.

\section{REFERENCES}

Pettit, J. H. S. and ReEs, R. J. W. (1964). Sulphone resistance in leprosy. Lancet, ii, 673.

TUASON, A. M. and RIVEra, J. N. (1965). Studies on breast milk sulphone level. Philipp. J. Lepr. ñ, 2. 